\title{
Diagnosis of Mercurial Teeth in a Possible Case of Congenital Syphilis and Tuberculosis in a 19th Century Child Skeleton
}

\author{
Stella Ioannou, Maciej Henneberg, Renata J. Henneberg, and Timothy Anson \\ Biological Anthropology and Comparative Anatomy Research Unit, The University of Adelaide, Adelaide, SA 5005, Australia \\ Correspondence should be addressed to Stella Ioannou; stella.ioannou@adelaide.edu.au
}

Received 2 February 2015; Accepted 17 March 2015

Academic Editor: Holger Schutkowski

Copyright (C) 2015 Stella Ioannou et al. This is an open access article distributed under the Creative Commons Attribution License, which permits unrestricted use, distribution, and reproduction in any medium, provided the original work is properly cited.

\begin{abstract}
Without the presence of "caries sicca," "sabre shins," and nodes/expansion of the long bones with superficial cavitation, differential diagnosis of venereal syphilis and tuberculosis (TB) may be difficult as various infections produce similar responses. However, congenital syphilis has distinctive features facilitating a diagnosis. A case study of remains of a juvenile European settler (probably male, 8-10 years old) (B70) buried in the 19th century and excavated in 2000 from the cemetery of the Anglican Church of St. Marys in South Australia is presented. B70 demonstrated that the two diseases might have been present in the same individual, congenital syphilis and TB. Widespread destruction of vertebral bodies and kyphosis-related rib deformations indicate advanced TB. Severe dental hypoplasia is limited to permanent incisors and first molars; there is pitting on the palate, periosteal reaction on the skull vault, and thinned clavicles. Dental signs are not limited to "screwdriver" central incisors and mulberry molars. Apical portions of the crowns of permanent upper, lower, central, and lateral incisors have multiple hypoplastic-disorganized defects; deciduous canines have severely hypoplastic crowns while possibly hypoplastic occlusal surfaces of lower deciduous second molars are largely destroyed by extensive caries. These dental abnormalities resemble teeth affected by mercurial treatment in congenital syphilitic patients as described by Hutchinson.
\end{abstract}

\section{Introduction}

In the past, the presence of numerous diseases and the lack of an effective form of treatment meant individuals could have suffered from more than one disease. This is especially the case in relation to chronic afflictions that could be combined with congenital diseases or acute infections. Syphilis and tuberculosis (TB) were two of these diseases. Significant in the past, both diseases continue to be an important public health problem. Syphilis, caused by the spirochete Treponema pallidum is typically transmitted through sexual contact. It can also be transmitted via the placenta from an infected mother to the fetus while she is in the most infectious stages of the disease (early primary or secondary stage). It is known as congenital syphilis [1]. Syphilis affects more than 12 million adults [2-4] and a million pregnancies each year [4-6]. Tuberculosis, a chronic infectious disease caused by Mycobacterium tuberculosis, is usually transmitted through the inhalation of airborne droplets filled with bacteria produced by infected individuals usually when coughing $[7,8]$.
Approximately 9 million new cases were registered and 1.5 million people died from tuberculosis in 2013 [9].

In most palaeopathological studies, skeletal signs of diseases are diagnosed to one nosological unit. This finds some justification in the fact that only a small portion of diseases leave recognizable signs on hard tissues of the body (bones and teeth). It is, however, possible to find signs of more than one affliction on a single skeleton [10]. When this is the case, study of skeletal involvement should not be the only method applied when making a differential diagnosis.

The differential diagnosis of syphilis and tuberculosis in palaeopathological specimens remains difficult as both diseases rarely affect or leave any signs on hard tissues of the body. In syphilis, only $1 / 3$ of individuals suffering from the tertiary stage of the disease will develop any bone lesions [10] while only about $3 \%$ to $5 \%$ of individuals with active TB will have skeletal changes [11-13]. The diagnostic characteristic of syphilis include "caries sicca," sclerosis, and pitting of the outer table of the cranial vault resulting from accumulation of stellate scarring $[11,14]$ creating a "worm eaten" appearance 
[14], tibial bowing, known as sabre shin [11, 15, 16], and the expansion of the long bones with nodes with superficial cavitation [14]. In tuberculosis diagnostic elements include osteolytic lesions on the thoracic and lumbar vertebral bodies $[10,13,17]$. Rib involvement including new bone formation, particularly periosteal reactions on the visceral surface [1821] is now considered in the diagnosis of tuberculosis [22].

Lesions of congenital syphilis can also be difficult to identify in skeletal samples as many pregnancies can result in stillbirths, abortion, or death $[15,23]$ and those skeletons are not often preserved. However, in those patients that do survive, the disease causes a disturbance in dental development producing abnormalities that are distinguishable features of the disease. The most recognisable are Hutchinson's incisors, while others include Moon's molars and Fournier's "mulberry" molars $[15,16,24-30]$. It is this characteristic that can support a differential diagnosis of the disease.

However, in cases where these diagnostic changes are not present, differential diagnosis of a specimen can be difficult. Our knowledge of the type of treatments used to combat syphilis and tuberculosis throughout history is well known. They used natural remedies, chemical compounds, and recently penicillin; however, our knowledge of the effects of these treatments on hard tissues has not been explored in depth.

Mercury has been used as early as the 27 th century BC in China [31]. It was recognised as a form of treatment for venereal diseases [31-33] prior to the introduction of salvarsan [34-37] and penicillin in the 20th century [38]. Mercury was provided to mothers during pregnancy [39] children, and infants in the form of ointments, calomel teething powders $[24,40,41]$, and injections [41, 42]. Mercurial poisoning was noted by Sir Hutchinson $[24,25,40]$ to grossly influence tooth development producing abnormalities of enamel formation (Figure 1). These may interfere with the expression of "classic" dental signs of congenital syphilis. When salvarsan was introduced, replacing mercury early in the 20th century, American military physicians recommended the use of mercury for the treatment of tuberculosis in adult patients $[43,44]$, but it is unclear how widespread this method of TB treatment became. There is no mention of its effects on dentition.

This paper presents a case study of the pathological lesions observed on a European subadult dated from the mid-19th to early 20th centuries who died during the early European colonization of South Australia, Australia [45]. The influences of mercury are considered in this case. In order to understand variation in skeletal lesions it is useful to consider the treatments used and their possible effects on the hard tissues of the body. This method may assist in a differential diagnosis.

\section{Materials and Methods}

The juvenile in this study (B70) was among a sample of 70 individuals excavated in 2000 from the cemetery of the Anglican Church of St. Marys, located at 1167 South Road, in St. Marys, Adelaide, South Australia. Many of those buried at the cemetery were in unmarked graves in a section of the grounds dating from 1846 to 1927, preventing individual identification [46]. These unmarked graves were considered colloquially as "paupers" graves due to their low socioeconomic status. Written records of burials can be found at the Church's Office. Signs of various infections were found on paleopathological analysis among the skeletal sample excavated including acquired syphilis, tuberculosis, pulmonary, and systemic infections. Some of these were also listed as causes of death in parish records [46]. Two thirds of the skeleton survives (Figure 2). Bone tissue is fragile and poorly preserved with some bones missing and others in fragments. The individual was aged by dental development, eruption, and formation using the Ubelaker chart [47] and primary ossification centres $[47,48]$. Sex of a subadult is difficult to estimate [49-51] and the methods proposed do not produce highly reliable results. Using the morphology of the symphyseal region of the mandible [52] and the shape of the mandible [53] in combination with the robusticity of long bones [54], the shape of the sciatic notch would have been used to aid in determining sex; however, the majority of the pelvis is missing. To determine the effects of mercury on hard tissues and possible pathologies, a search of the literature was conducted and compared to B70.

\section{Results}

B70 is probably a subadult male. According to dental eruption and formation, the child is between eight and ten years of age. An osteoblastic lesion approximately $15 \mathrm{~mm}$ in diameter is present on the cranial vault (possible periosteal reaction) on the posterior portion of the left parietal bone close to the lambdoid suture (Figure 3). Pitting is present on the maxillary alveolar process (Figure 4) and on both sides of the palate; however, it is stemming from the root of the right first upper molar (Figure 5).

3.1. Dentition. B70 demonstrates mixed dentition. The maxillary upper right central incisor is the only tooth missing postmortem. The dentition consists of a left central incisor, partially erupted lateral right and left incisors, deciduous canines, first and second premolars, permanent first molars, and second permanent molar germs. The maxillary left central incisor demonstrates narrow and rounded medial and distal edges and is slightly crescentic in shape. It is hypoplastic. Its incisive edge is slightly narrowed with minute mamelons and multiple notching. The incisal $1 / 3$ of the labial surface has thinner, discoloured (darker) enamel with pitting hypoplasia. This part of the crown forms a few months after birth [55]. The remainder of the labial surface has three transverse hypoplastic lines (Figure 4). On the lingual surface, the incisal $1 / 3$ of the crown has thinner enamel. It is separated from the remainder of the crown by a distinct hypoplastic grove that extends to the mesial and distal surfaces. The lateral right incisor is narrow and hypoplastic. The right and left maxillary lateral incisors on the labial view, approximately a third of the distance from the apical point of the crown, are a round indentation in the enamel. The lateral left incisor has a central pit about $1 \mathrm{~mm}$ in diameter and is notched mesially. Crowns of the upper deciduous canines have wide hypoplastic discoloured (darker) areas beginning below 


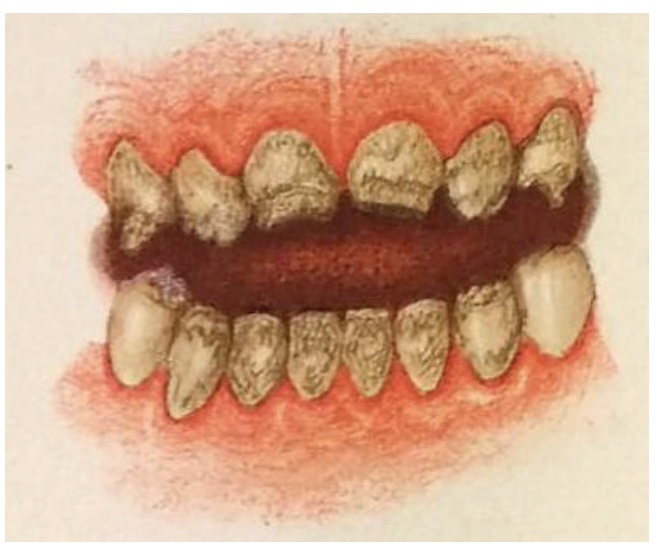

(a)

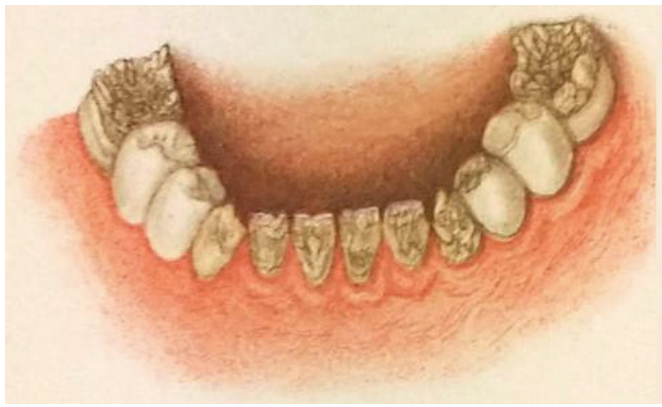

(c)

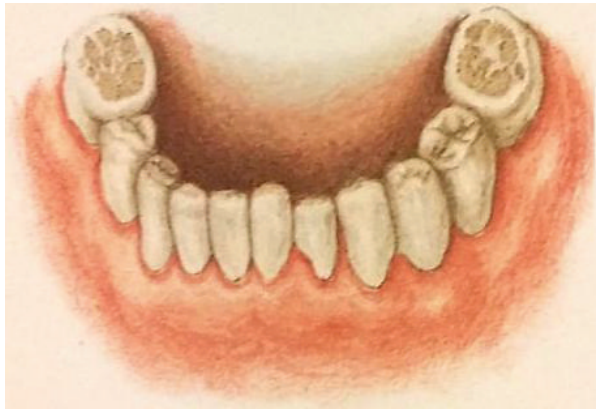

(e)

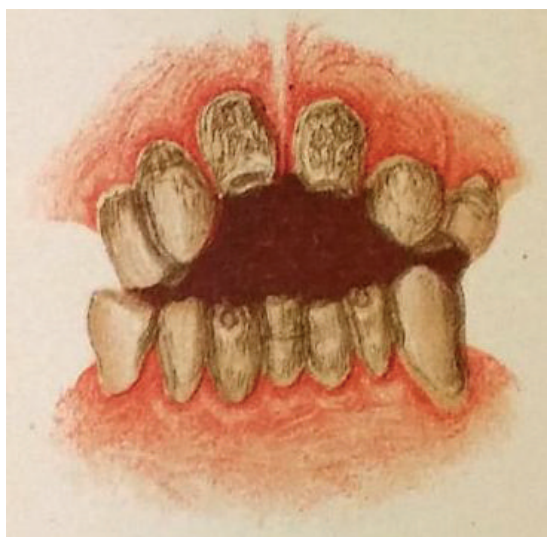

(b)

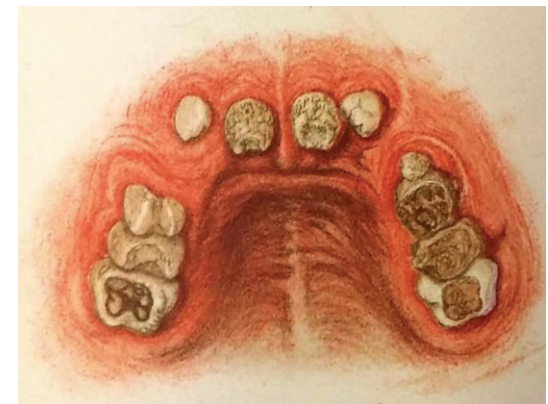

(d)

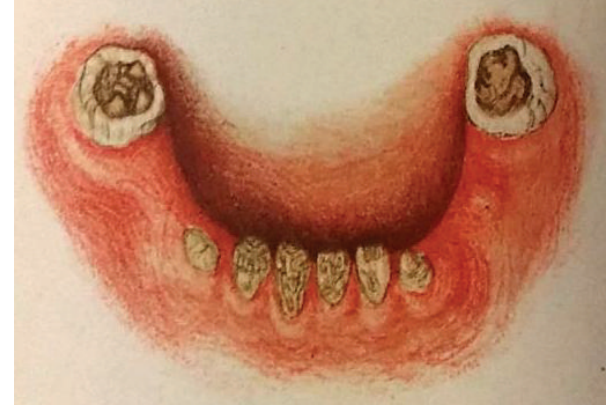

(f)

FIGURE 1: Diagrams of mercurial teeth seen in mercurial treated congenital syphilitic patients by Hutchinson. Hutchinson, J. 1878. Illustrations of clinical surgery consisting of plates, photographs, woodcuts, diagrams, and so forth: illustration of surgical diseases, symptoms and accidents, also operative and other methods of treatment, with descriptive letterpress, London, J. \& A. Churchill.

the tip of the crown and extending down to about $1 / 3$ of the crown indicating that the changes occurred after birth (Figures 4 and 5). All maxillary premolars appear normal. Both first permanent upper molars have grossly abnormal crowns. Their occlusal surfaces have widespread hypoplastic defects (Figures 6(a) and 6(b)). Extensive carious lesions are present on the mesial half of the occlusal surface of the right upper first permanent molar and small carious lesions on the occlusal surface of the left first permanent molar. Distinctive lines of thinner enamel are present on both permanent molars, separating the upper part of the crown (occlusal surface) from the rest of the crown. Areas constricted by the lines are smaller than the extent of the lower parts of the crowns. This indicates that the changes occurred shortly after birth [55]. The crown morphology of the second permanent molar germs is normal.

Mandibular dentition includes all permanent incisors, deciduous molars, canines, first permanent molars, and second permanent germs. The permanent incisors are hypoplastic with small mamelons and linear and pitted hypoplasia on the crowns (Figure 7(a)). Distal 2/3 crowns of lower deciduous canines are very narrow with thinner hypoplastic enamel and appear conical in shape (Figure 7(a)). The remaining proximal $1 / 3$ has rather normal enamel. The proximal 1/3 of deciduous canine crowns has normal enamel. First deciduous molars show discolouration but no caries. 


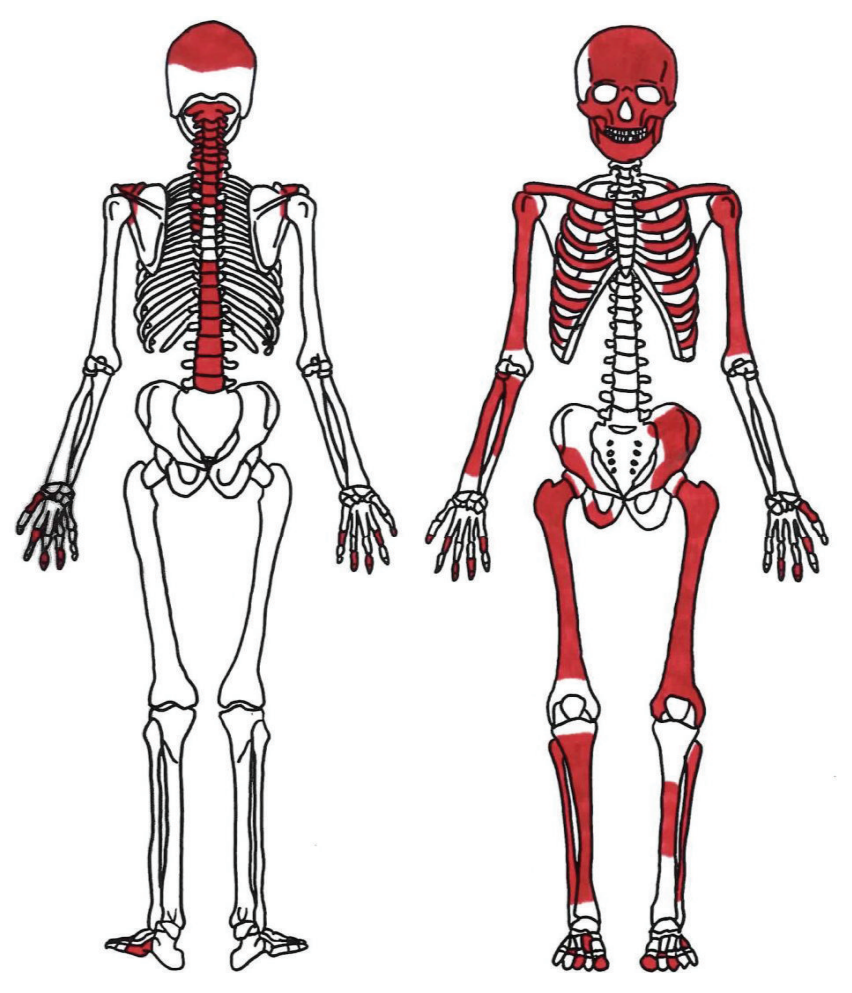

FIGURE 2: Shaded areas represent bones present.

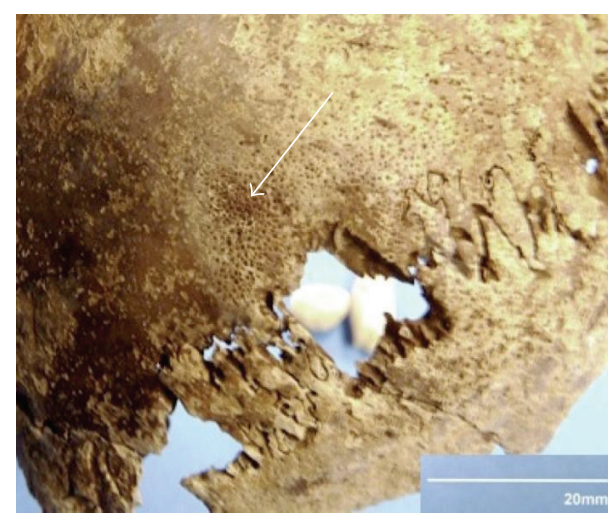

Figure 3: Periosteal reaction approximately $15 \mathrm{~mm}$ in diameter on posterior portion of the left parietal bone close to the lambdoid suture. On close inspection there is no erosion of the cortical bone (Lamina externa).

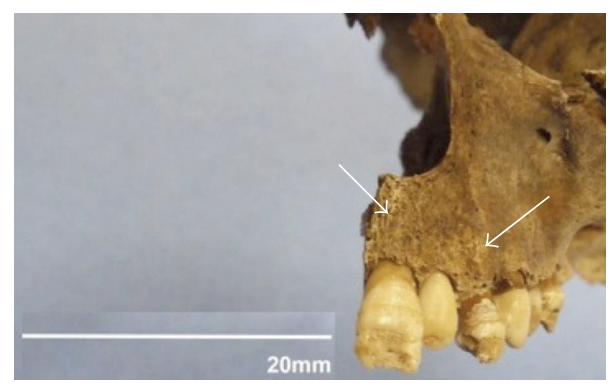

FIgURE 4: Pitting on maxillary alveolar process due to inflammatory response.

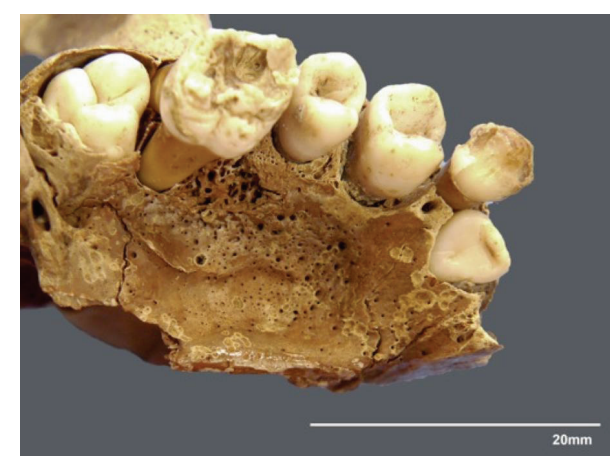

FIGURE 5: Pitting on palate stemming from permanent first molar due to inflammatory response.

The second deciduous molars and canines have extensive carious cavities. The first permanent molars occlusal surfaces are grossly hypoplastic (Figure 7(b)). Similarly to the maxillary dentition, hypoplastic changes indicate that they have occurred within the first few months after birth. The right lower permanent molar has an extensive carious lesion extending through most of the centre of the occlusal surface. A small carious pit in the centre of the mesial half of the occlusal surface is present in left (Figure 7(b)). The crown morphology of both lower second molar germs is normal. Resorption of the alveolar bone is observed (Figure 7(a)).

3.2. Clavicle and Ribs. Morphology of the clavicle and several ribs appears abnormal. Thinning of the sternal end of the clavicle is evident (Figure 8). There is a small proliferative change on the upper portion of the 3rd rib. Localised inflammatory reaction is present on the right side, superior surface on the 4th or 5th rib (Figure 9). Added grooving is evident on the superior surface of several ribs.

3.3. Vertebral Column. There are extensive pathological changes on the vertebral column. The vertebral bodies of C5Th3 show damage to their anterior parts. Signs of remodelling on C6 and C7 could indicate signs of healing (Figure 10). Cervical vertebrae $\mathrm{C} 1-\mathrm{C} 4$ show no pathological signs. Vertebral bodies of Th3-Th4 are largely destroyed, Th4 more so than Th3. Bodies of all other thoracic vertebrae, except Th10 and Th11, are absent, but it cannot be ascertained whether this was due to taphonomic processes or due to actual pathological destruction. Zygapophyseal joints between what are likely to be Th5-Th6 are completely fused on both sides and there are no vertebral bodies (Figure 11(a)). The left zygapophyseal joints of Th6-Th7 are also fused, while the right side is missing. Th9 is possibly in fragments. Vertebral body of Th10 is partially destroyed. Th11 and Th12 are represented by small fragments.

Two bodies and two arches of the lumbar vertebrae are preserved. One body has two deep pits on its anterior surface, which appear lytic (Figure 11(b)). The other body and the arches show no pathological signs. The body and right lateral mass of the first sacral segment are preserved without obvious pathological signs. The left lateral mass of the sacrum 


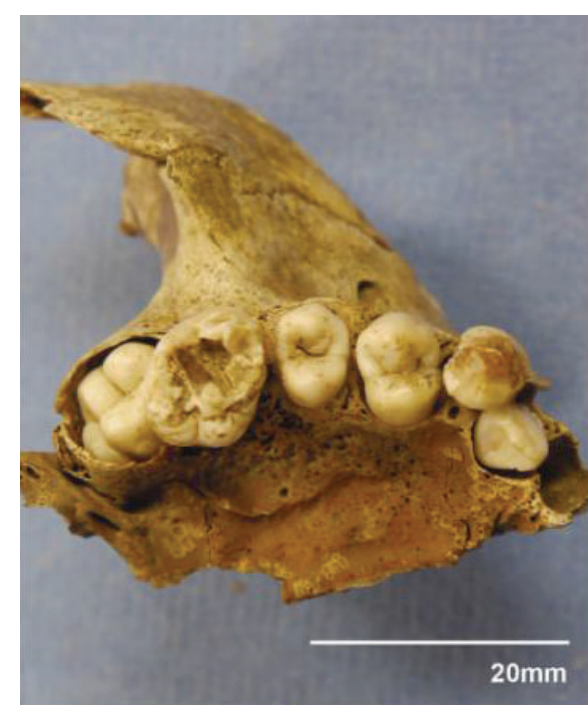

(a)

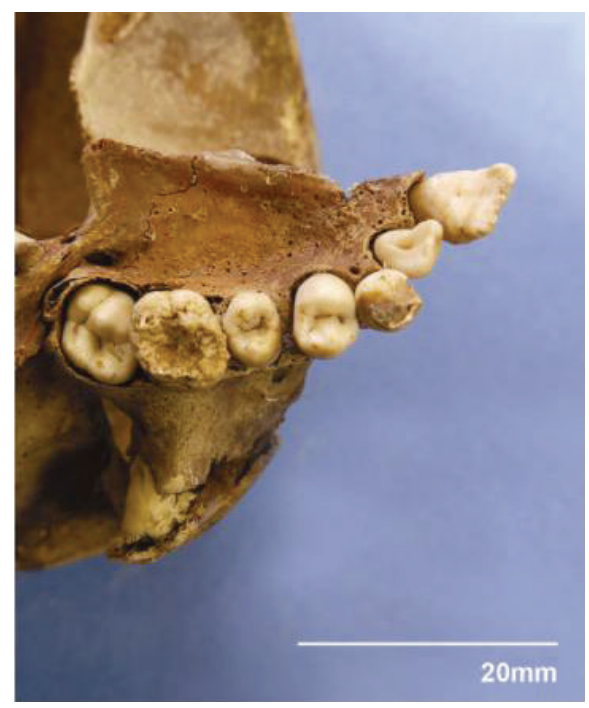

(b)

FiguRE 6: (a) Right permanent upper first molar showing signs of dysplastic occlusal enamel. (b) Left permanent upper first molar with hypoplastic defects characteristic of dysplastic occlusal enamel.

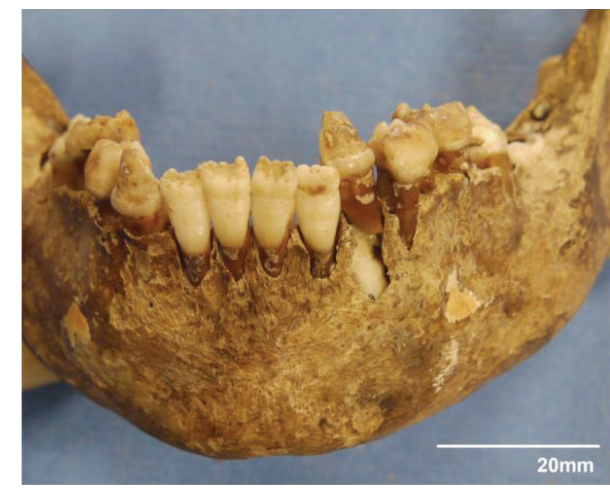

(a)

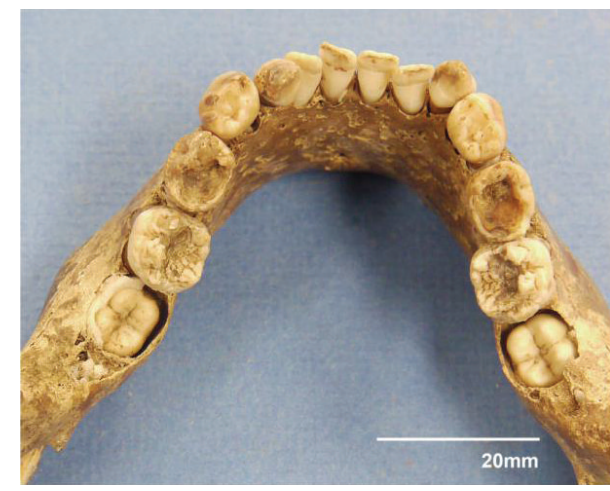

(b)

Figure 7: (a) Angled lower border of mandible, similar in shape to male juvenile mandible A.668 studied by Loth and Henneberg [52, Figure 2]. (b) Lower first permanent molars grossly hypoplastic.

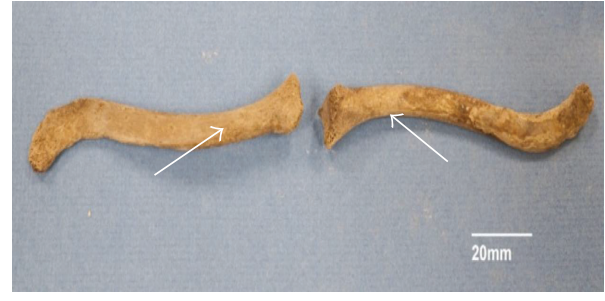

FIGURE 8: Thinning at sternal ends of clavicles.

is completely fused with the left ilium at the sacroiliac joint. There are no clear signs of any inflammatory processes. Right sacroiliac joint appears normal. The first sacral segment has a normal body. Bodies of other sacral segments are preserved in fragments and no pathological signs were observed. No pathological signs were noted on the long bones.

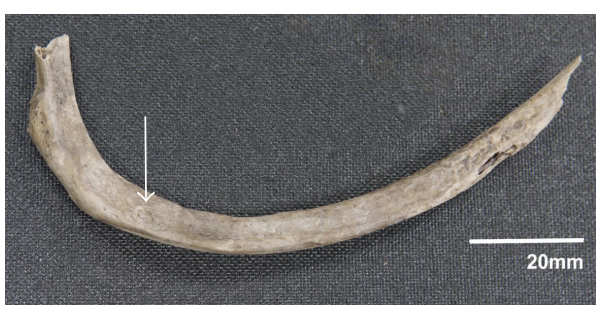

FIGURE 9: Inflammatory reaction of inferior surface on 4 th or 5 th rib.

\section{Discussion}

4.1. Differential Diagnosis. In this case, it is possible that B70, a mid-19th to early 20th century specimen, suffered from multiple conditions. Differential diagnosis of B70 includes 


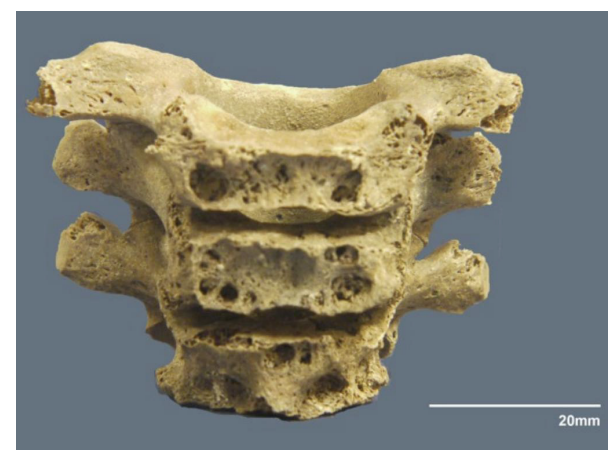

FIGURE 10: Destruction of anterior bodies of lower cervical vertebrae.

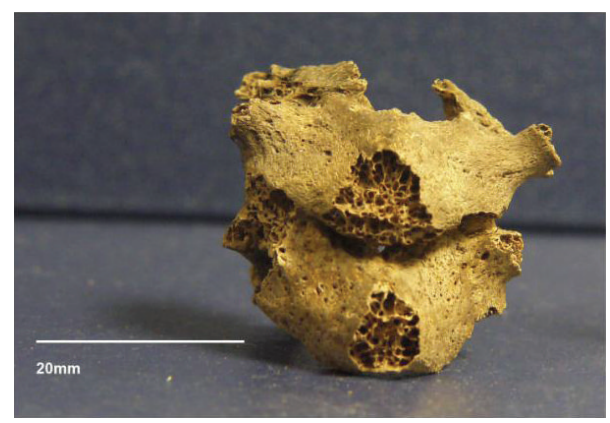

(a)

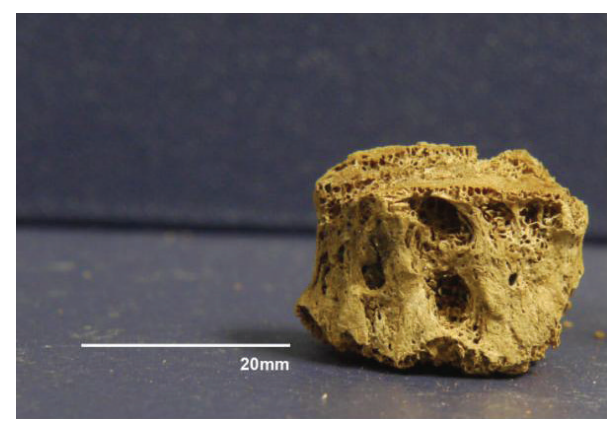

(b)

FIGURE 11: (a) Fusion of zygapophyseal joints between Th5 and Th6 completely fused with no vertebral bodies. (b) Lumbar vertebral body with deep pits.

infectious and noninfectious diseases including congenital syphilis, tuberculosis, brucellosis, rickets, and fluorosis.

Lesions in congenital syphilis can vary from periosteal reactions and osteomyelitis in the early stages [56-58] and cranial gummatous lesions and frontal bossing of the bone, destruction of the nasal bridge, a high arch palate, sternoclavicular thickening, and tibial bowing (sabre shin) in the late stage of the disease $[15,16,59-61]$. With the exception of a possible localised periosteal reaction on the cranial vault of B70, there is minimal skeletal evidence to support the differential diagnosis of congenital syphilis.

The dental changes in B70, although not "typical" (Hutchinson's incisors, Moon's molars, or Fournier's mulberry molars), may still be a result of congenital syphilis through the mercurial treatment of the disease. Hutchinson recognised that mercury produced enamel defects in particular pairs of teeth. In severe cases it would affect dentine, too. With the tooth enamel deficient, the tooth would appear rugged, pitted, and dirty [40]. The first permanent upper and lower molars are the "test teeth" for mercurial influence, similar to the upper central incisors considered to be the "test teeth" in congenital syphilis. The crown enamel is deficient, with dentin growing through and revealing numerous discoloured tubercles [40]. A distinct demarcated line separating healthy enamel from diseased enamel was also evident on the sides of the molars. In severe cases, the tooth could appear dwarfed. Upper and lower incisors and canines were usually affected, with enamel deficiencies occurring below a line that would cross them at the same level; however, premolars usually escape all damage [40]. Hutchinson also noted that it was common for both syphilitic and mercurial teeth to be present at the same time which may have caused confusion among physicians [40]. He did not specify, however, exact ages or developmental stages of dentition at which the changes occurred.

B70's dentition closely resembles the descriptions and images (Figure 1(c)) of congenital syphilis patients treated with mercury as provided by Hutchinson. The first upper and lower permanent molars demonstrate enamel deficiency across the occlusal surface exposing multiple tubercles, appearing rugged, pitted, and dirty. There is a clear distinction between diseased and healthy enamel on all four molars and all three canines. All upper and lower incisors exhibit enamel deficiencies apical to the linear enamel hypoplasia. All upper premolars appear normal. Taking into account individual variation in formation of deciduous and permanent tooth crowns, the most likely age at which the changes in B70's dentition occurred is shortly after birth. The cervical ends of enamel on all teeth appear normal, suggesting that ameloblasts were disturbed during the early years of life [62]. Tips of deciduous canine crowns seem to be normally formed, but the crown area below them is hypoplastic in contrast to first deciduous lower molars whose morphology is normal. Permanent tooth changes affected apical or occlusal portions of specific crowns that form in the first few months of life. It is possible that the type of enamel damage to the first permanent molars in B70 could be classified as cuspal enamel hypoplasia [62]; however, to confirm this, scanning electron microscopy would need to be performed.

Clinical presentations of congenital syphilis present similar dental features to those seen in B70. These include multiple notching or serrated edges which were seen in five patients [63] pitted enamel hypoplasia of the upper central and lateral incisors and primary and secondary dental caries on numerous teeth [64]. Narrowing and a reduction of the dentinoenamel junction of the permanent incisors and first molars, with a reduction in the size of the crowns and constriction of mamelons, was also noted by Sarnat and Shaw [27].

In comparison to palaeopathological specimens, similarities to B70 include the round indentation in the enamel on the maxillary right and left lateral incisors [65-67] and pitted enamel hypoplasia in the lower right incisors. Others include linear enamel hypoplasia in all four incisors with a deficiency 
in enamel above (apically) a hypoplastic line [67, 68], the distinct demarcation between healthy and diseased enamel, and severe enamel deficiencies exposing multiple tubercles in molars [67].

The lack of skeletal lesions on limb bones of B70 could be supported by clinical cases of late congenital syphilis, which found no periosteal lesions or perichondritis $[69,70]$. This may be related to the stage of infection in maternal syphilis and transmission [69]. The later stages of the disease in the mother produce lesser risk of infection [15] and possibly less severity.

Tuberculosis is typically diagnosed by osteolytic skeletal lesions in the vertebral bodies and in large joints of palaeopathological specimens [11]. The most common manifestations of skeletal tuberculosis in children are spondylitis, osteomyelitis, and involvement of the joints [11, 71]. In children, common areas affected by the disease included the knee [72, 73], lytic circumscribed lesions of the cranium $[7,74,75]$, spine [71, 76], hip [73, 77], elbow [78], and ribs [76]. There is no documentation with regard to dental abnormalities found in juvenile tuberculosis [7, 79]. Dental changes briefly mentioned include linear enamel hypoplasia $[80,81]$, carious lesions, and decreased enamel thickness [80].

Comparing B70 to skeletal signs of tuberculosis, osteolytic lesions evident on the thoracic and lumbar vertebrae resemble few juvenile specimens [81, 82]. A circumscribed periosteal lesion on the superior surface of rib four or five in B70 is similar to that found in the case of TB in the Hamann-Todd Osteological Collection [83]. However, no lytic lesions were apparent on the cranial vault of B70, neither was there involvement of the joints as in the cases mentioned above. Linear enamel hypoplasia and dental abnormalities as seen in B70 have not been noted in clinical cases of primary tuberculosis [84-86]. There are no documented palaeopathological cases of congenital tuberculosis. This may be due to the rarity of the disease and the low survival rates of infants born with the condition [87-89]. Therefore, congenital TB is not known to produce extensive hypoplastic defects on incisal edges nor on occlusal surfaces of teeth. It is likely that B70 suffered from TB acquired during childhood.

While we know that mercury has been used in the treatment of tuberculosis, its descriptions and suggested use begin from 1908 and they do not seem to be widespread. B70 was buried in a cemetery dating from 1846 to 1927 , so it is unlikely that mercury's use in treatment of tuberculosis would be the cause of described dental changes.

Brucellosis affects different areas of the skeleton in adults and in children. In adults the spine or sacroiliac joint is more commonly affected, whereas in children, the knee, hip, and ankle joints are more common [90-94]. While the left sacroiliac joint is fused in B70, who is a child, there do not appear to be any signs of inflammation and there are no other pathologies that resemble those seen in brucellosis; therefore, it is difficult to make a confident differential diagnosis. However, the sacral segments that are present do not show any pathology. There are also no lesions present on the knee joint or the rest of the appendicular skeleton, and thus brucellosis is unlikely.
Rickets is a vitamin D deficiency, affecting the metabolism of calcium and phosphorus and the mineralization of bone. Skeletal changes include bending deformities $[95,96]$, metaphyseal flaring, and porosity of cortical bone $[11,95,97]$. These changes can affect the cranial vault, long bones, pelvis, ribs, and vertebrae. In conjunction with the skeletal pathologies of rickets, abnormalities in dentition are common, particularly linear enamel hypoplasia, pitting, dental opacities, and caries [98-100]. Considering that there are no bending deformities, flaring, porosity of the cortical bone, and dental opacities and while hypoplasia is not limited to linear defects, rickets in B70 is unlikely.

Fluorosis is a disturbance of dental development resulting from ingestion of large quantities of fluoride [11, 101]. These dental abnormalities include opaque white patches in the enamel. This can result in pitting, striations, and widespread brown staining [101-104]. Skeletal pathologies include abnormal bone formations on the appendicular or axial skeleton, mostly linked with the insertions of tendons and ligaments [11]. In clinically diagnosed cases of fluorosis in children, skeletal manifestations included osteopenia, growth lines, and sclerosis [105-107]. Considering that there is no widespread dental staining nor skeletal lesions relating to fluorosis, it is unlikely that B70 suffered from fluorosis.

\section{Conclusion}

B70 was excavated from St. Marys cemetery, from a section of the grounds dating from 1846 to 1927, when European settlers colonized South Australia. B70 was buried at the expense of the Government in a section of the cemetery referred to as the "paupers" graveyard [108]. Burial records of St. Marys indicate that treponemal diseases and tuberculosis were present among the skeletal sample B70 originated from and other skeletons (B10, B6, and B53c), demonstrated possible cases of treponemal disease [46]. Considering that B70 was excavated from the pauper's section of the graveyard and multiple diseases were present in the sample (syphilis and tuberculosis), it is probable that B70 suffered from multiple diseases in congenital syphilis and tuberculosis. The significance of this skeleton is that it displays dental signs that are not typically seen in congenital syphilitic cases. It is possible that this specimen displays the effects of mercury that was used to treat the disease. It is possible that chemical elements or compounds have not been considered in paleopathology to have an effect on hard tissues. Hopefully, this paper will reintroduce an interest in the work of Hutchinson who noted that mercury, used to treat syphilis, plays a role in the disruption of enamel formation. Mercury's effects are separate from tooth development (size and shape), caused by the disease and yet they are indicative of the disease through its treatment. Therefore, Hutchinson's incisors, Moon's molars, and Fournier's molars are not the only dental abnormalities that should be considered in the diagnosis of syphilis when examining specimens from antiquity up to the introduction and usage of modern treatments. 


\section{Conflict of Interests}

The authors declare that there is no conflict of interests regarding the publication of this paper.

\section{Acknowledgments}

This paper has been written while the first author was supported by the Faculty of the Health Sciences, University of Adelaide doctoral scholarship. The authors thank Dr. Sadaff Sassani, BDS, for discussion of the interpretation of mercurial teeth.

\section{References}

[1] N. J. L. Fiumara, "Syphilis in newborn children," Clinical Obstetrics \& Gynecology, vol. 18, no. 1, pp. 183-189, 1975.

[2] A. C. Gerbase, J. T. Rowley, D. H. L. Heymann, S. F. B. Berkley, and P. Piot, "Global prevalence and incidence estimates of selected curable STDS," Sexually Transmitted Infections, vol. 74, supplement 1, pp. S12-S16, 1998.

[3] C. R. Woods, "Syphilis in children: congenital and acquired," Seminars in Pediatric Infectious Diseases, vol. 16, no. 4, pp. 245257, 2005.

[4] K. A. Fenton, R. Breban, R. Vardavas et al., "Infectious syphilis in high-income settings in the 21st century," The Lancet Infectious Diseases, vol. 8, no. 4, pp. 244-253, 2008.

[5] G. Schmid, "Economic and programmatic aspects of congenital syphilis prevention," Bulletin of the World Health Organization, vol. 82, no. 6, pp. 402-409, 2004.

[6] H. Saloojee, S. Velaphi, Y. Goga, N. Afadapa, R. Steen, and O. Lincetto, "The prevention and management of congenital syphilis: an overview and recommendations," Bulletin of the World Health Organization, vol. 82, no. 6, pp. 424-430, 2004.

[7] H. Dawson and K. R. Brown, "Childhood tuberculosis: a probable case from late mediaeval Somerset, England," International Journal of Paleopathology, vol. 2, no. 1, pp. 31-35, 2012.

[8] A. R. Punnoose, C. Lynm, and R. M. Golub, "Tuberculosis," The Journal of the American Medical Association, vol. 309, no. 9, p. 938, 2013.

[9] World Health Organization, Global Tuberculosis Report 2014, World Health Organization, Geneva, Switzerland, 2014.

[10] R. T. Steinbock, Paleopathological Diagnosis and Interpretation: Bone Diseases in Ancient Human Populations, Charles C Thomas, Springfield, Ill, USA, 1976.

[11] D. J. Ortner, Identification of Pathological Conditions in Human Skeletal Remains, Academic Press, San Diego, Calif, USA, 2003.

[12] C. A. Roberts and J. E. Buikstra, The Bioarchaeology of Tuberculosis: A Global View on a Reemerging Disease, University Press of Florida, Gainesville, Fla, USA, 2003.

[13] K. L. Holloway, R. J. Henneberg, M. de Barros Lopes, and M. Henneberg, "Evolution of human tuberculosis: a systematic review and meta-analysis of paleopathological evidence," HOMO, vol. 62, no. 6, pp. 402-458, 2011.

[14] C. J. Hackett, "An introduction to diagnostic criteria of syphilis, treponarid and yaws (treponematoses) in dry bones, and some implications," Virchows Archive A: Pathological Anatomy and Histology, vol. 368, no. 3, pp. 229-241, 1975.
[15] N. J. Fiumara and S. Lessell, "Manifestations of late congenital syphilis: an analysis of 271 patients," Archives of Dermatology, vol. 102, no. 1, pp. 78-83, 1970.

[16] N. J. Fiumara and S. Lessell, "The stigmata of late congenital syphilis: an analysis of 100 patients," Sexually Transmitted Diseases, vol. 10, no. 3, pp. 126-129, 1983.

[17] K. L. Holloway, K. Link, F. Rühli, and M. Henneberg, "Skeletal lesions in human tuberculosis may sometimes heal: an aid to palaeopathological diagnoses," PLoS ONE, vol. 8, no. 4, Article ID e62798, 2013.

[18] A. L. Santos and C. A. Roberts, "A picture of tuberculosis in young Portuguese people in the early 20th century: a multidisciplinary study of the skeletal and historical evidence," The American Journal of Physical Anthropology, vol. 115, no. 1, pp. 38-49, 2001.

[19] M. A. Kelley and M. Y. El-Najjar, "Natural variation and differential diagnosis of skeletal changes in tuberculosis," The American Journal of Physical Anthropology, vol. 52, no. 2, pp. 153-167, 1980.

[20] M. A. Kelley and M. S. Micozzi, "Rib lesions in chronic pulmonary tuberculosis," American Journal of Physical Anthropology, vol. 65, no. 4, pp. 381-386, 1984.

[21] A. L. Santos and C. A. Roberts, "Anatomy of a serial killer: differential diagnosis of tuberculosis based on rib lesions of adult individuals from the coimbra identified skeletal collection, Portugal," The American Journal of Physical Anthropology, vol. 130, no. 1, pp. 38-49, 2006.

[22] C. Roberts, D. Lucy, and K. Manchester, "Inflammatory lesions of ribs: an analysis of the Terry Collection," The American Journal of Physical Anthropology, vol. 95, no. 2, pp. 169-182, 1994.

[23] N. J. Fiumara, W. L. Flemming, J. G. Downing, and F. L. Good, "The incidence of prenatal syphilis at the Boston City Hospital," The New England journal of medicine, vol. 247, no. 2, pp. 48-52, 1952.

[24] J. Hutchinson, Syphilis, Cassell \& Company, London, UK, 1887.

[25] J. Hutchinson, Syphilis, Cassell \& Company, London, UK, 2nd edition, 1909.

[26] W. D. Johnston, B. G. Anderson, and P. F. McAlenney, "Effects of congenital syphilis on the teeth and associated structures in children," American Journal of Orthodontics and Oral Surgery, vol. 27, no. 12, pp. 667-680, 1941.

[27] B. G. Sarnat and N. G. Shaw, "Dental development in congenital syphilis," The American Journal of Diseases of Children, vol. 64, no. 5, pp. 771-788, 1942.

[28] S. Hillson, C. Grigson, and S. Bond, "Dental defects of congenital syphilis," American Journal of Physical Anthropology, vol. 107, no. 1, pp. 25-40, 1998.

[29] A. Freiman, D. Borsuk, B. Barankin, G. H. Sperber, and B. Krafchik, "Dental manifestations of dermatologic conditions," Journal of the American Academy of Dermatology, vol. 60, no. 2, pp. 289-298, 2009.

[30] L. Pessoa and V. Galvão, "Unusual presentation of more common disease/injury: clinical aspects of congenital syphilis with Hutchinson's triad," BMJ Case Reports, vol. 2011, pp. 1-3, 2011.

[31] F. Buret, Syphilis in Ancient and Prehistoric Times: Translated from the French, with Notes by A.H Ohmann-Dumesnil, edited by: F. A. Davis, F.A. Davis Company, Philadelphia, Pa, USA, 1891.

[32] M. S. Claiborne, Hierinymus Fracastor's Syphylis from the Original Latin: A Translation in Prose of This Immortal Poem, The Philmar Company, St. Louis, Mo, USA, 1911. 
[33] E. H. Hudson, "Historical approach to the terminology of syphilis," Archives of Dermatology, vol. 84, no. 4, pp. 545-562, 1961.

[34] W. Evans, "Salvarsan in syphilis," The Lancet, vol. 179, no. 4612, pp. 152-153, 1912.

[35] G. Stopford-Taylor and R. W. Mackenna, "Salvarsan in the treatment of syphilis," The Lancet, vol. 177, no. 4578, pp. 14121416, 1911.

[36] "Salvarsan," The Lancet, vol. 182, no. 4705, pp. 1268-1269, 1913.

[37] M. Wardle, "Salvarsan," British Medical Journal, vol. 1, no. 2632, p. 1372, 1911.

[38] J. F. Mahoney, R. C. Arnold, and A. D. Harris, "Penicillin treatment of early syphilis: a preliminary report," American Journal of Public Health and the Nations Health, vol. 33, no. 12, pp. 1387-1391, 1943.

[39] S. Sheill, "Our responsibilities in the prevention of inherited syphilis; with illustrative cases," The Dublin Journal of Medical Science, vol. 130, no. 1, pp. 15-22, 1910.

[40] J. Hutchinson, Illustrations of Clinical Surgery: Consisting of Plates, Photographs, Woodcuts, Diagrams etc., Illustrating Surgical Diseases, Symptoms and Accidents, Also Operative and Other Methods of Treatment, with Descriptive Letterpress, J. \& A. Churchill, London, UK, 1878.

[41] F. J. Lambkin, “The treatment of syphilis," The British Medical Journal, vol. 1, no. 2506, pp. 123-123, 1909.

[42] “The preparation of finely divided calomel," The British Medical Journal, vol. 1, no. 3049, p. 713, 1919.

[43] G. G. Moseley, "Mercury in the treatment of tuberculosis," California State Journal of Medicine, vol. 7, no. 9, pp. 338-340, 1909.

[44] B. L. Wright, "The treatment of tuberculosis by the administration of mercury," The Journal of the American Medical Association, vol. LI, no. 22, pp. 1854-1856, 1908.

[45] T. J. Anson and M. Henneberg, "A solution for the permanent storage of historical skeletal remains for research purposes: a South Australian precedent that keeps scientists and the Church community happy," Australian Archaeology, vol. 58, pp. 15-18, 2004.

[46] T. J. Anson, The Bioarchaeology of the St. Mary's Free Ground Burials: Reconstruction of Colonial South Australian Lifeways, Department of Anatomical Sciences, University of Adelaide, 2004.

[47] D. H. Ubelaker, Human Skeletal Remains: Excavation, Analysis, Interpretation, Aldine Publishing Company, Chicago, Ill, USA, 1978.

[48] J. E. Buikstra and D. H. Ubelaker, Standards for Data Collection from Human Skeletal Remains: Proceedings of a Seminar at the Field Museum of Natural History, Arkansas Archaeological Survey Research Series 44, Arkansas Archeological Survey, Fayetteville, Ark, USA, 1994.

[49] H. Schutkowski, "Sex determination of infant and juvenile skeletons: I. Morphognostic features," American Journal of Physical Anthropology, vol. 90, no. 2, pp. 199-205, 1993.

[50] H. F. V. Cardoso and S. R. Saunders, "Two arch criteria of the ilium for sex determination of immature skeletal remains: a test of their accuracy and an assessment of intra- and inter-observer error," Forensic Science International, vol. 178, no. 1, pp. 24-29, 2008.

[51] D. Vlak, M. Roksandic, and M. A. Schillaci, "Greater sciatic notch as a sex indicator in juveniles," The American Journal of Physical Anthropology, vol. 137, no. 3, pp. 309-315, 2008.
[52] S. R. Loth and M. Henneberg, "Sexually dimorphic mandibular morphology in the first few years of life," The American Journal of Physical Anthropology, vol. 115, no. 2, pp. 179-186, 2001.

[53] H. Schutkowski, "Sex determination of infant and juvenile skeletons: I. Morphognostic features," The American Journal of Physical Anthropology, vol. 90, no. 2, pp. 199-205, 1993.

[54] A. Coussens, T. Anson, R. M. Norris, and M. Henneberg, "Sexual dimorphism in the robusticity of long bones of infants and young children," Anthropological Review, vol. 65, pp. 3-16, 2002.

[55] M. M. Ash and S. J. Nelson, Wheeler's Dental Anatomy, Physiology, and Occlusion, W.B. Saunders, Philadelphia, Pa, USA, 9th edition, 2003.

[56] D. Armangil, F. E. Canpolat, S. Yigit, H. A. Demir, and M. Ceyhan, "Early congenital syphilis with isolated bone involvement: a case report," The Turkish Journal of Pediatrics, vol. 51, no. 2, pp. 169-171, 2009.

[57] S. Basu and A. Kumar, "Varied presentations of early congenital syphilis," Journal of Tropical Pediatrics, vol. 59, no. 3, pp. 250254, 2013.

[58] P. G. Agrawal, R. Joshi, V. D. Kharkar, and M. V. Bhaskar, "Congenital syphilis: the continuing scourge," Indian Journal of Sexually Transmitted Diseases and AIDS, vol. 35, no. 2, pp. 143145, 2014.

[59] M. Dorne and S. J. Zakon, "Enlargement of one sternoclavicular articulation as a valuable clinical sign of late prenatal (congenital) syphilis," Archive of Dermatology and Syphilology, vol. 32, no. 4, pp. 602-604, 1935.

[60] E. C. Dax and R. M. Stewart, "The sign of the clavicle," The British Medical Journal, vol. 1, no. 4084, pp. 771-772, 1939.

[61] S. M. Laird, "Late congenital syphilis; an analysis of 115 cases," The British Journal of Venereal Diseases, vol. 26, no. 3, pp. 143145, 1950.

[62] A. R. Ogden, R. Pinhasi, and W. J. White, "Gross enamel hypoplasia in molars from subadults in a 16th-18th century London graveyard," The American Journal of Physical Anthropology, vol. 133, no. 3, pp. 957-966, 2007.

[63] R. C. V. Robinson, "Congenital syphilis," Archives of Dermatology, vol. 99, no. 5, pp. 599-610, 1969.

[64] B. Liweń and J. Owczarek, "Congenital syphilis in a multiple children family-own case," Dental and Medical Problems, vol. 49, no. 3, pp. 439-442, 2012.

[65] Y. S. Erdal, "A pre-Columbian case of congenital syphilis from Anatolia (Nicaea, 13th century AD)," International Journal of Osteoarchaeology, vol. 16, no. 1, pp. 16-33, 2006.

[66] K. C. Nystrom, "Postmortem examinations and the embodiment of inequality in 19th century United States," International Journal of Paleopathology, vol. 1, no. 3-4, pp. 164-172, 2011.

[67] J. S. Gaul and K. Grossschmidt, "A probable case of congenital syphilis from 18th century Vienna," International Journal of Paleopathology, vol. 6, no. 1, pp. 34-43, 2014.

[68] K. P. Jacobi, D. C. Cook, R. S. Corruccini, and J. S. Handler, "Congenital syphilis in the past: slaves at Newton Plantation, Barbados, West Indies," The American Journal of Physical Anthropology, vol. 89, no. 2, pp. 145-158, 1992.

[69] M. Chaudhary, B. Kashyap, and P. Bhalla, "Congenital syphilis, still a reality in 21st century: a case report," Journal of Medical Case Reports, vol. 1, article 90, 2007.

[70] N. Chowdhary, B. K. Rani, K. S. Mukunda, and N. K. Kiran, "Early detection of congenital syphilis," Journal of Indian Society 
of Pedodontics and Preventive Dentistry, vol. 32, no. 4, pp. 333337, 2014.

[71] H. E. Teo and W. C. Peh, "Skeletal tuberculosis in children," Pediatric Radiology, vol. 34, no. 11, pp. 853-860, 2004.

[72] E. B. Hoffman, J. Allin, J. A. B. Campbell, and F. M. Leisegang, "Tuberculosis of the knee," Clinical Orthopaedics \& Related Research, vol. 398, pp. 100-106, 2002.

[73] C. Guillou-Debuissona, S. Salannea, C. Maréchala, E. Laportea, I. Claudeta, and E. Grouteaua, "Osteoarticular tuberculosis: a differential diagnosis of idiopathic juvenile arthritis," Archives de Pédiatrie, vol. 17, no. 11, pp. 1553-1558, 2010.

[74] D. J. Ortner and W. G. J. Putschar, Identification of Pathological Conditions in Human Skeletal Remains, Smithsonian Institution Press, Washington, DC, USA, 1981.

[75] G. Pálfi, Z. Bereczki, D. J. Ortner, and O. Dutour, "Juvenile cases of skeletal tuberculosis from the Terry Anatomical Collection (Smithsonian Institution, Washington, D.C., USA)," Acta Biologica Szegediensis, vol. 56, no. 1, pp. 1-12, 2012.

[76] M. E. Lewis, "Tuberculosis in the non-adults from RomanoBritish Poundbury Camp, Dorset, England," International Journal of Paleopathology, vol. 1, no. 1, pp. 12-23, 2011.

[77] Y. Teklali, Z. F. El Alami, T. El Madhi, H. Gourinda, and A. Miri, "Peripheral osteoarticular tuberculosis in children: 106 casereports," Joint Bone Spine, vol. 70, no. 4, pp. 282-286, 2003.

[78] H. S. Hosalkar, N. Agrawal, S. Reddy, K. Sehgal, E. J. Fox, and R. A. Hill, "Skeletal tuberculosis in children in the Western world: 18 new cases with a review of the literature," Journal of Children's Orthopaedics, vol. 3, no. 4, pp. 319-324, 2009.

[79] H. Dabernat and É. Crubézy, "Multiple bone tuberculosis in a child from predynastic Upper Egypt (3200 BC)," International Journal of Osteoarchaeology, vol. 20, no. 6, pp. 719-730, 2010.

[80] V. Formicola, Q. Milanesi, and C. Scarsini, "Evidence of spinal tuberculosis at the beginning of the fourth millennium BC from Arene Candide cave (Liguria, Italy)," American Journal of Physical Anthropology, vol. 72, no. 1, pp. 1-6, 1987.

[81] V. Matos, C. Marques, and C. Lopes, "Severe vertebral collapse in a juvenile from the graveyard (13th/14th-19th centuries) of the São Miguel church (Castelo Branco, Portugal): differential palaeopathological diagnosis," International Journal of Osteoarchaeology, vol. 21, no. 2, pp. 208-217, 2011.

[82] S. Andronikou, S. Jadwat, and H. Douis, "Patterns of disease on MRI in 53 children with tuberculous spondylitis and the role of gadolinium," Pediatric Radiology, vol. 32, no. 11, pp. 798-805, 2002.

[83] M. A. Kelley and M. S. Micozzi, "Rib lesions in chronic pulmonary tuberculosis," The American Journal of Physical Anthropology, vol. 65, no. 4, pp. 381-386, 1984.

[84] I. Dimitrakopoulos, L. Zouloumis, N. Lazaridis, D. Karakasis, G. Trigonidis, and L. Sichletidis, "Primary tuberculosis of the oral cavity," Oral Surgery, Oral Medicine, Oral Pathology and Oral Radiology, vol. 72, no. 6, pp. 712-715, 1991.

[85] M. D. Mignogna, L. L. O. Muzio, G. Favia et al., "Oral tuberculosis: a clinical evaluation of 42 cases," Oral Diseases, vol. 6, no. 1, pp. 25-30, 2000.

[86] F. A. Ito, C. R. de Andrade, P. A. Vargas, J. Jorge, and M. A. Lopes, "Primary tuberculosis of the oral cavity," Oral Diseases, vol. 11, no. 1, pp. 50-53, 2005.

[87] F. E. Amick, M. W. Alden, and L. K. Sweet, "Congenital tuberculosis," Pediatrics, vol. 6, no. 1, pp. 384-390, 1950.
[88] G. H. Kang and J. G. Chi, "Congenital tuberculosis: report of an autopsy case," Journal of Korean Medical Science, vol. 5, no. 1, pp. 59-64, 1990.

[89] R. Figueroa-Damián and J. L. Arredondo-García, "Neonatal outcome of children born to women with tuberculosis," Archives of Medical Research, vol. 32, no. 1, pp. 66-69, 2001.

[90] E. Galanakis, K. L. Bourantas, S. Leveidiotou, and P. D. Lapatsanis, "Childhood brucellosis in north-western Greece: a retrospective analysis," European Journal of Pediatrics, vol. 155, no. 1, pp. 1-6, 1996.

[91] M. F. Geyik, A. Gür, K. Nas et al., "Musculoskeletal involvement in brucellosis in different age groups: a study of 195 cases," Swiss Medical Weekly, vol. 132, no. 7-8, pp. 98-104, 2002.

[92] M. P. Franco, M. Mulder, R. H. Gilman, and H. L. Smits, "Human brucellosis," The Lancet Infectious Diseases, vol. 7, no. 12, pp. 775-786, 2007.

[93] M. C. Bouaziz, M. F. Ladeb, M. Chakroun, and S. Chaabane, "Spinal brucellosis: a review," Skeletal Radiology, vol. 37, no. 9, pp. 785-790, 2008.

[94] Y. A. Al-Eissa, A. M. Kambal, A. A. Alrabeeah, A. M. A. Abdullah, N. A. Al-Jurayyan, and N. M. Al-Jishi, "Osteoarticular brucellosis in children," Annals of the Rheumatic Diseases, vol. 49, no. 11, pp. 896-900, 1990.

[95] S. Mays, M. Brickley, and R. Ives, "Skeletal manifestation of rickets in infants and young children in a historic population from England," The American Journal of Physical Anthropology, vol. 129, no. 3, pp. 362-374, 2006.

[96] S. Mays, M. Brickley, and R. Ives, "Growth and vitamin D deficiency in a population from 19th century Birmingham, England," International Journal of Osteoarchaeology, vol. 19, no. 3, pp. 406-415, 2009.

[97] D. J. Ortner and S. Mays, "Dry-bone manifestations of rickets in infancy and early childhood," International Journal of Osteoarchaeology, vol. 8, no. 1, pp. 45-55, 1998.

[98] H. M. Mackay, "Vitiman D defficency, dental caries and tonsillar enlargemnt: a clinical investigation of some late effects of rickets," The Lancet, vol. 218, no. 5649, pp. 1230-1235, 1931.

[99] M. M. Eliot, S. P. Souther, B. G. Anderson, and S. S. Arnim, "A study of the teeth of a group of school children previously examined for ricket," The American Journal of Diseases of Children, vol. 48, no. 4, pp. 713-729, 1934.

[100] W. K. Seow, J. P. Brown, D. A. Tudehope, and M. O'Callaghan, "Dental defects in the deciduous dentition of premature infants with low birth weight and neonatal rickets," Pediatric Dentistry, vol. 6, no. 2, pp. 88-92, 1994.

[101] J. Littleton, "Paleopathology of skeletal fluorosis," The American Journal of Physical Anthropology, vol. 109, no. 4, pp. 465-483, 1999.

[102] I. J. Møller, "Fluorides and dental fluorosis," International Dental Journal, vol. 32, no. 2, pp. 135-147, 1982.

[103] J. Littleton and B. Frohlich, "An Analysis of dental pathology and diet on historic Bahrain," Paléorient, vol. 15, no. 2, pp. 5975, 1989.

[104] J. Zou and J. W. Ashley, "Fluorosis," in Pathobiology of Human Disease, L. M. M. N. Mitchell, Ed., pp. 893-898, Academic Press, San Diego, Calif, USA, 2014.

[105] M. Teotia, S. P. S. Teotia, and K. B. Kunwar, "Endemic skeletal fluorosis," Archives of Disease in Childhood, vol. 46, no. 249, pp. 686-691, 1971. 
[106] J. M. Pettifor, C. M. Schnitzler, F. P. Ross, and G. P. Moodley, "Endemic skeletal fluorosis in children: hypocalcemia and the presence of renal resistance to parathyroid hormone," Bone and Mineral, vol. 7, no. 3, pp. 275-288, 1989.

[107] Y. Wang, Y. Yin, L. A. Gilula, and A. J. Wilson, "Endemic fluorosis of the skeleton: radiographic features in 127 patients," The American Journal of Roentgenology, vol.162, no. 1, pp. 93-98, 1994.

[108] J. Davies, A Pioneer Walk through the Churchyard of St. Mary's, South Road, St. Mary's Church, Adelaide, Australia, 1991. 

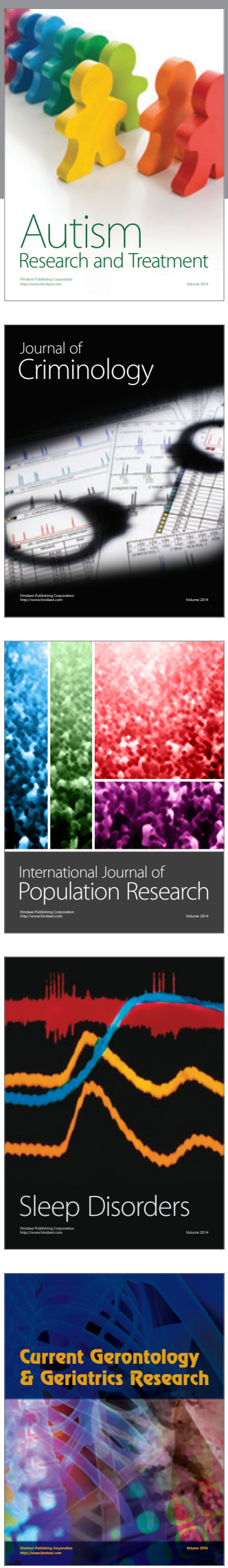
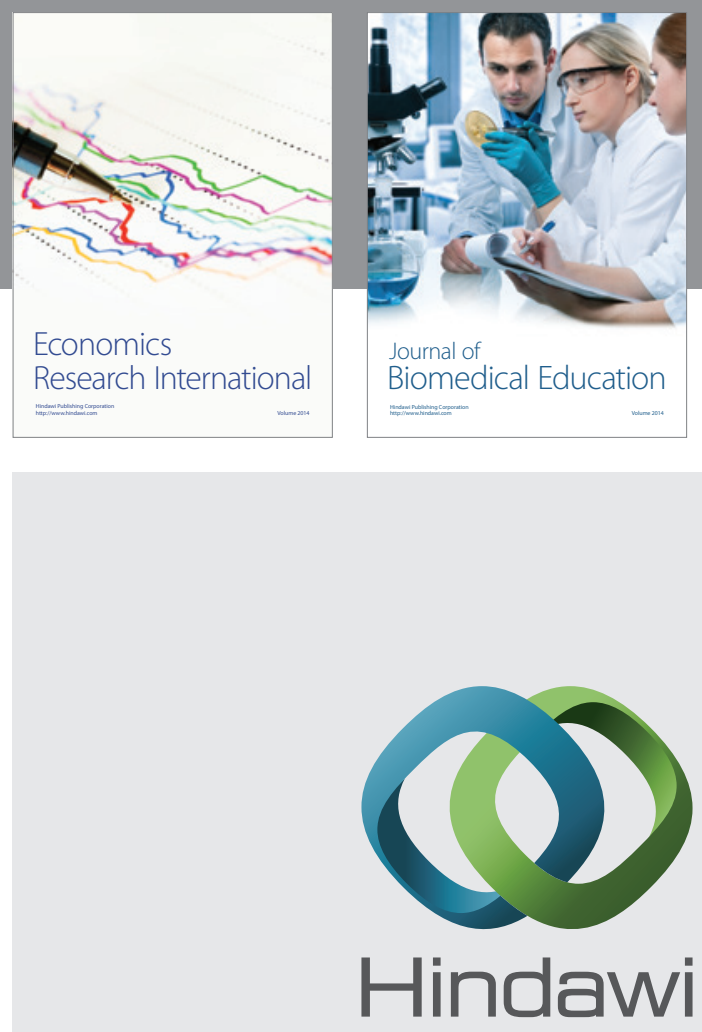

Submit your manuscripts at

http://www.hindawi.com
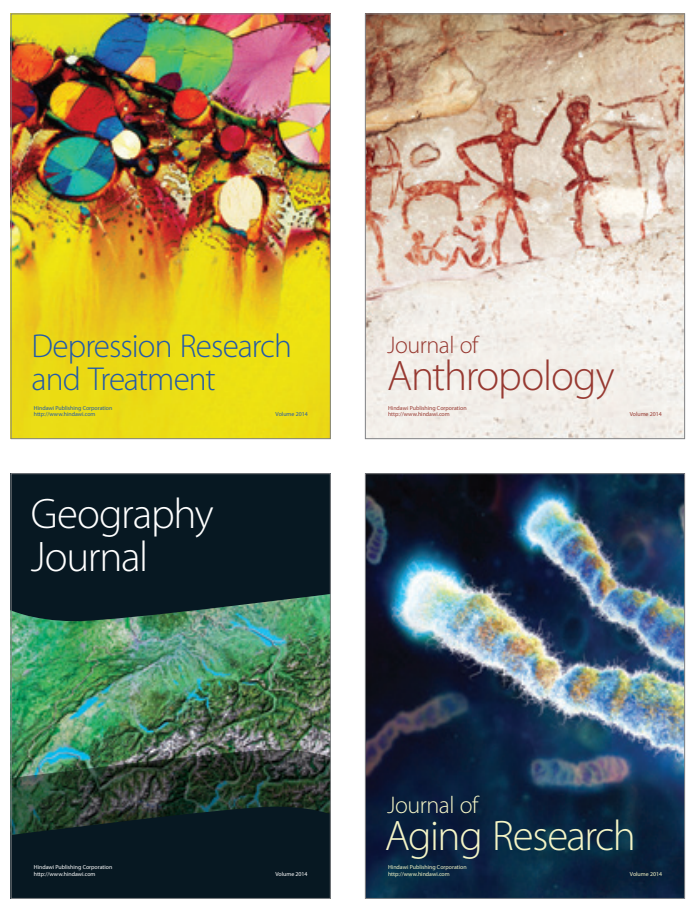
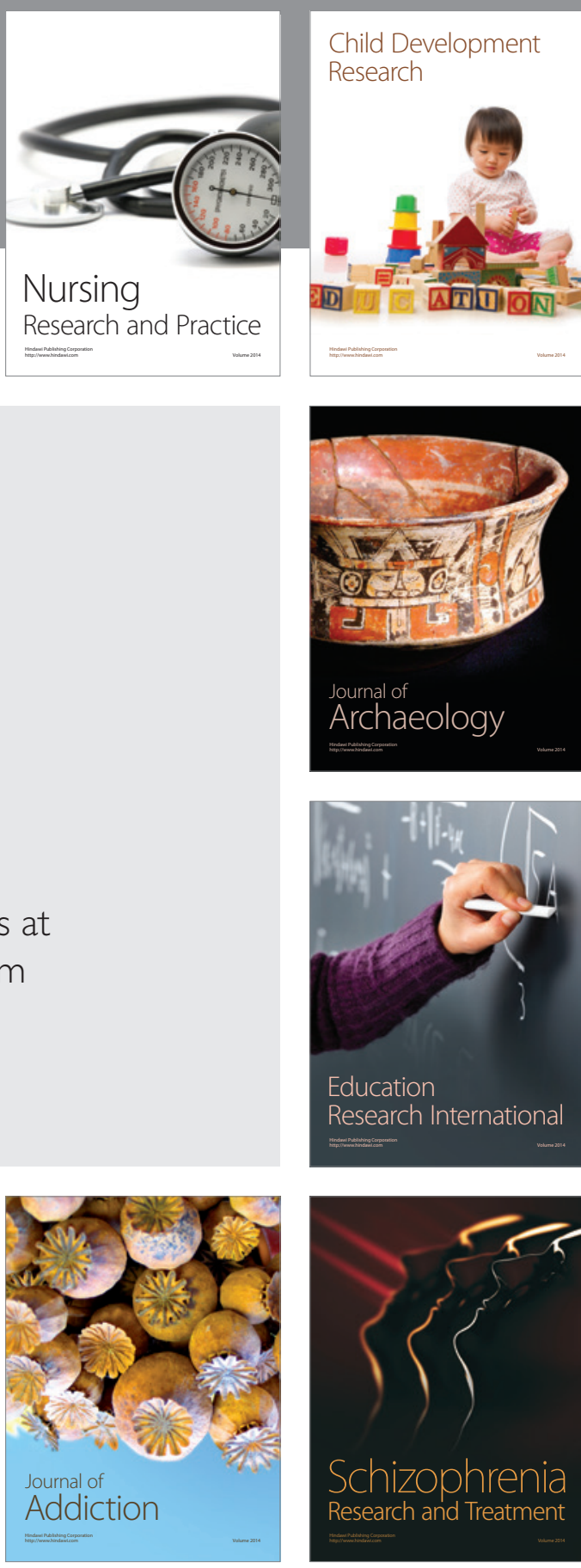

(D)
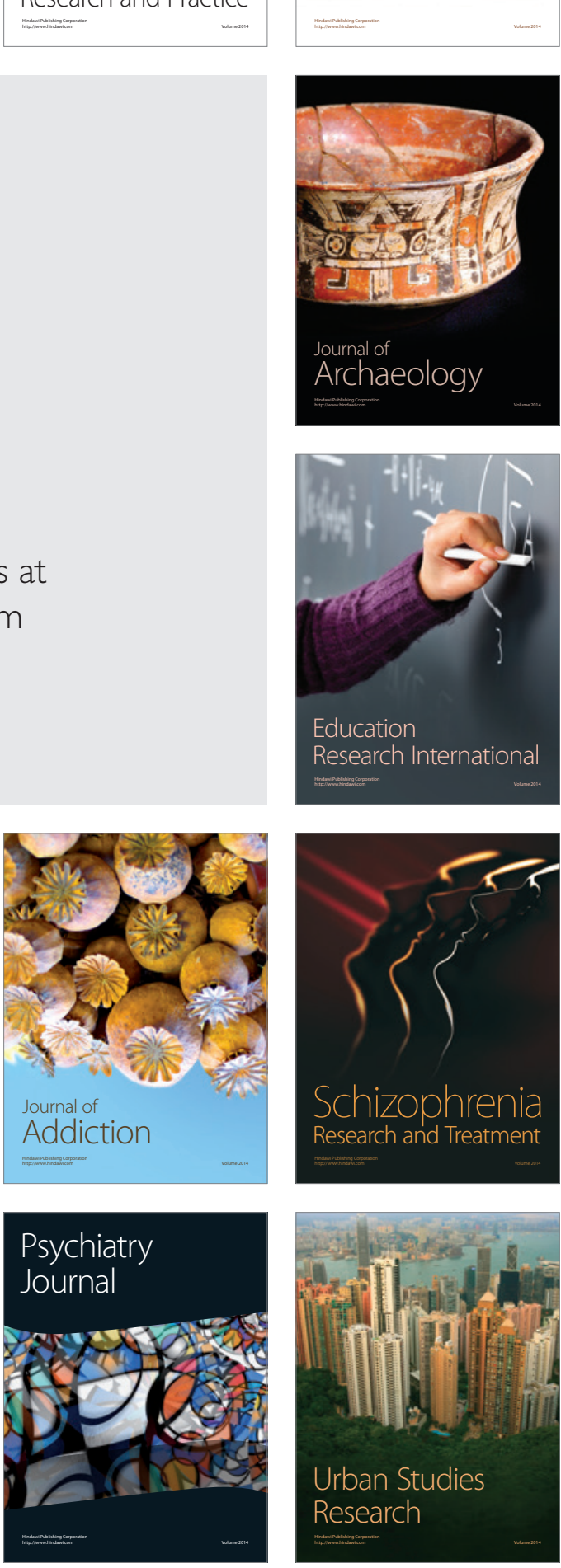